\title{
A prática docente e a Pedagogia: reflexões acerca do cotidiano dos professores do Ensino Técnico
}

\author{
Ailton Gonçalves Reis*
}

\begin{abstract}
Resumo
A formação de professores tem sido uma constante nas discussões sobre a educação. Nesse sentido, parece haver uma relação intrínseca entre o sucesso ou insucesso de um determinado processo de ensino e a formação de professores. Para o Ensino Técnico, porém, essa preocupação com a formação de professores tem deixado a desejar. Nesse contexto, este trabalho, resultado de Dissertação de Mestrado em Educação, tem como objetivo mostrar a pertinência da formação pedagógica para os professores do Ensino Técnico, com vistas a uma formação integral dos alunos egressos dos cursos técnicos. No que diz respeito à metodologia, optou-se pela pesquisa descritiva, caracterizada como um estudo de caso, realizada em um dos campi do Instituto Federal do Amazonas - IFAM, cujos participantes foram 15 professores e 30 alunos do Ensino Técnico. Os instrumentos utilizados para a coleta de dados foram entrevistas e questionários previamente elaborados. O referencial teórico se apoia em autores que advogam a formação integral do homem e não uma formação meramente técnica, tais como: Arroyo, Contreras, Franco, Marques, Hypólito, Tardif. Espera-se, assim, contribuir na formação de professores para o Ensino Técnico de Nível Médio.

Palavras-chaves: Formação Professores; Formação Pedagógica; Ensino Técnico; Prática Docente; Cidadania.
\end{abstract}

\section{A teaching practice and pedagogy: reflections about the daily teachers lives of Technical Teaching}

\begin{abstract}
Teacher education has been a constant in discussions about education. In this sense, there seems to be an intrinsic relationship between the success or failure of a given process of teaching and teacher education. For Technical Education, however, this concern with teacher education has been less than optimal. In this context, this work, the result of Dissertation in Education, aims to show the relevance of pedagogical training for teachers of Technical Education, aiming an integral formation of students graduating from technical courses. With respect to methodology we chose the descriptive research, featured as a case study conducted in one of campi of the Federal Institute of Amazonas -IFAM, whose participants were 15teachers and30studentsof Technical Education. The instruments used for data collection were interview sand questionnaires, previously elaborated. The theoretical frame work relies on authors who advocate the integral formation of man and not a merely technical training, such as Arroyo, Contreras, Franco Marques, Hypólito, Tardiff. Thus, it is expected to contribute to the training of teachers for Technical Education Middle Level.

Keywords: Teacher Education; Pedagogical Training; Technical Education; Teaching Practice; Citizenship.
\end{abstract}

\section{Introdução}

No âmbito do movimento da formação de professores, os educadores produziram e evidenciaram concepções avançadas sobre a formação do educador, destacando o caráter sóciohistórico necessário para essa formação e também a necessidade de um profissional com amplos conhecimentos, com pleno domínio e compreensão da realidade de seu tempo, com desenvolvimento da consciência crítica que lhe permita interferir e transformar as condições da escola, da educação e da sociedade.

Com essa concepção emancipadora de educação, o processo formativo de professores avançou no sentido de buscar e superar as dicotomias entre professores e especialistas, pedagogia e licenciatura, pois a escola avançou na democratização das relações de poder em seu interior e, daí, para a construção de novos projetos coletivos.

Como parte importante dessa construção teórica a partir das transformações concretas no campo da escola, foi construída a concepção do profissional da educação que tem na docência e no trabalho pedagógico suas particularidades e especificidades. Dessa forma, a formação do educador não pode ser desvinculada das grandes questões sociais e do movimento dos trabalhadores pela construção de uma nova sociedade pautada na justiça, na democracia e na igualdade (SAVIANI, 1985).

Nesse contexto, o Ensino Técnico não pode estar à margem desse objetivo e, logo, a formação

* Professor efetivo do Instituto Federal do Amazonas-IFAM. Endereço eletrônico: reis.ailton@ifam.edu.br 
de professores para essa modalidade de ensino deve, necessariamente, se preocupar em formar professores a partir dessa perspectiva.

Para este trabalho, formulamos como hipótese principal a necessidade de uma formação pedagógica para os professores do Ensino Profissional, como premissa para a formação integral do Técnico de Nível Médio, que atenda não somente às demandas de qualificação do atual processo produtivo de base técnico-científica, mas também à formação do indivíduo enquanto ser histórico-social. Dentre os objetivos destacamos a indicação de elementos teórico-metodológicos que constituem a dimensão pedagógica da relação trabalho-educação-cidadania numa perspectiva de formação holística. A metodologia de pesquisa compreendeu estudo bibliográfico e estudo de caso.

$\mathrm{Na}$ perseguição dos objetivos propostos, o trabalho está dividido em três partes, que, juntamente com a Introdução e as Considerações Finais, se completam. A primeira apresenta um breve histórico sobre o professor como trabalhador e as mudanças que ocorreram no histórico da profissão. Já na segunda parte, apresenta-se o professor como profissional da educação e a importância da pedagogia na formação desse profissional; e, por fim, na terceira parte, apresentam-se e discutem-se os dados obtidos na pesquisa de campo.

\section{Historicizando o professor como trabalhador profissional}

Em qualquer profissão, a qualificação é vista como algo primordial e por isso, geralmente, o sujeito que deseja se profissionalizar precisa preparar-se, fazendo cursos e especializações para se destacar, em sua área, no momento de trabalho. Em geral, advoga-se que o profissional deveria primeiro aprimorar-se, procurando dominar as teorias que vão formar o bom trabalhador. A seguir, vem a parte prática, ou seja, depois que ele estiver preparado, quando se sentir apto a praticar aquilo que assimilou teoricamente, pode aplicar em sua prática profissional (MARCELO GARCIA, 1999).

Porém a história da formação docente mostra que a prática precedeu a teoria, pois esta foi exigida apenas quando a profissão de professor passou a ser responsabilidade do Estado.

Conforme Arroyo (2000), no Brasil, o mestre do ofício de ensinar nascia e se fazia antes de ser reconhecido como tal pelo Estado. A nomeação era o reconhecimento oficial de uma instrução já existente, particular e livre. Em muitos casos, o Estado oficializava o ensino que já era feito por mestres livres, escolhidos e pagos pelos pais e, sobretudo, por mestres feitos e formados na arte do ofício de ensinar, ensinando.

Quando o governo, enquanto regulador da vida social, tomou para si o controle da educação, a qual passa a ser um dever do Estado e um direito do cidadão, o trabalhador da educação passa a ser submetido ao sistema público. Ao longo desse processo, as relações de trabalho dos educadores vão sendo alteradas e, de autônomos, eles passam a vender sua força de trabalho e se submeter à organização da empresa pública, passando a ser assalariados do governo e, ao perder sua autonomia, parecem transformar-se em proletários.

Ainda conforme Arroyo (2000), no momento em que há uma constituição ainda incipiente do que chamamos hoje de escolas, os primeiros professores passam a fazer parte de um sistema que tem suas normas e interesses próprios. Faz-se necessário, então, conhecer e cumprir as normas e regras ditadas por seu empregador: o Estado. Na medida em que este se auto atribui os direitos de nomear, suspender professores e criar cadeiras, quebram-se os vínculos com a família e os alunos e reforça-se o vínculo entre o professor e o Estado. Essa mudança de conexão cria um profissional que deixa de prestar contas à comunidade e passa a fazê-lo para o Estado, de quem, agora, é totalmente dependente financeiramente. Dessa forma,

Ao mesmo tempo em que o professorado vai se constituindo em um corpo profissional, assalariado pelo o Estado, as comunidades vão perdendo o controle sobre a moral, o comportamento e o modo de vida dos professores e sobre o ensino que deve ser ministrado por seus componentes (HYPÓLITO, 1991, p. 31).

Nota-se, então, um distanciamento cada vez mais crescente entre o professor e a comunidade, causado pela estatização da profissão. Talvez, por isso, seja comum, até hoje, encontrarmos professores não-integrados à profissão docente enquanto prática social, não responsáveis perante a comunidade e seus colegas, não se envolvendo com os projetos coletivos escolares, o que é próprio da individualidade tão propagada pelo pensamento neoliberal.

Com a obrigatoriedade de apresentar títulos 
acadêmicos, com o passar do tempo a categoria profissional é dividida em titulados e não titulados. Os titulados obtiveram o direito a um salário mais alto, mesmo que os outros fizessem o mesmo tipo de trabalho que os primeiros, até com mais qualidade.

Diante desse quadro que se apresenta o trabalho do professor, acreditamos ser necessário mencionar as condições do trabalho docente; para isso, é necessário nos remetermos aos modos pelos quais se organiza o processo de trabalho na escola.

Hypólito (1991) aponta algumas categorias importantes para a análise do trabalho docente. Apoiado em outros estudos, principalmente na noção de trabalho em Marx, o autor vai tecendo as condições do trabalho do professor. Para ele, há uma proletarização dos professores à medida que estes vendem sua força de trabalho, produzindo mais-valia. No entanto, o que os difere de um perfeito proletário é o fato de ainda possuir boa parte do controle do seu trabalho.

Uma outra discussão sobre esse processo de proletarização é encontrada em Contreras (2002). Conforme este autor, esse processo vai se construindo paulatinamente com a perda, por parte dos professores, de todas as qualidades que os caracterizavam como profissionais, assim como a deterioração de todos os meios que possibilitavam um trabalho de qualidade.

Embora não se possa falar de unanimidade entre os autores que defendem a teoria de proletarização dos professores, a tese básica dessa posição é a consideração de que os docentes, enquanto categoria, sofrer amou estão sofrendo uma transformação, tanto nas características de suas condições de trabalho como nas tarefas que realizam, que os aproxima de cada vez das condições $e$ interesses da classe operária (CONTRERAS, 2002, p. 33).

Ao contrário de Hypólito (1991), Contreras (2002) não aborda a questão da mais valia como causa principal da proletarização docente, mas sim a própria perda da gestão de seu trabalho, resultante da racionalização do processo educativo, considerando que o professor fica dependente de especialistas que pensam e traçam a forma como deve ser desenvolvida a docência. Dessa forma, é nesse momento de perda que o professor mais se aproxima de um operário, visto que percebemos claramente nesse contexto os conceitos-chave que explicam o fenômeno de racionalização do trabalho operário, quais sejam: “(a) a separação entre a concepção e execução no processo produtivo; b) a desqualificação, como perda dos conhecimentos e habilidades para planejar, compreender e agir sobre a produção; e c) a perda de controle sobre seu próprio trabalho" (CONTRERAS, 2002, p. 35).

Outro fator que faz os professores se aproximarem dos outros trabalhadores é a forma com que eles se organizam a fim de gerar modos de resistência na defesa de seus interesses coletivos e individuais.

Esta dinâmica de resistência e organização é o que, na opinião dos teóricos da proletarização, permitiria igualar os professores à classe operária, já que não só seguiram um processo de desqualificação equivalente, mas também que tal desqualificação os transforma em uma categoria com interesses e procedimentos de resistência equivalente aos do proletariado (CABRERA; JIMÉNEZ JAÈN apud CONTRERAS, idem, p. 39).

Isto posto, percebe-se que a história do profissional professor vai se organizando de forma sinonímica a qualquer outro profissional, isto é, a partir da perda da autonomia na forma de exercer a profissão, ficando à mercê de outros profissionais ou da própria condição socioeconômica em que está inserido.

\section{O professor como profissional da educação}

Aqui vamos considerar o professor como um profissional do ensino e, por isso, detentor de vários conhecimentos necessários à boa docência $\mathrm{e}$ também de vários direitos que, na maioria das vezes, não são respeitados.

Conforme Marques (2003), o exercício da docência ainda é considerado um fruto de capacidades pessoais, ligadas mais aos traços de personalidade ou da motivação que levam os indivíduos a abraçar essa carreira, sem reconhecer as competências necessárias de que dispõe para exercer uma profissão como outra qualquer. Por isso, ao reportar-se ao trabalho docente, ele afirma:

É comum insistir-se na distinção entre o educador do ser humano e o professor, mestre-escola, transmissor de conhecimentos acabados e técnicos 
instrumentais. Tradicionalmente vista como missão, ou como vocação, e sendo aos poucos substituída a dimensão religiosa aí implícita por uma disposição psicológica, de certo idealismo individual sublimado pela consciência cívica, a dedicação às tarefas do educar pareceria pairar acima vicissitudes próprias do que necessitam ganhar a vida por seu trabalho (MARQUES, 2003, p. 56-7).

Por outro lado, Tardif (2002) advoga que a atividade dos professores é um exercício profissional complexo, composto, na realidade, de várias atividades pouco visíveis socialmente, no qual a experiência constitui a expressão de aprendizagem profissional e, pelo contato diário com os alunos e colegas de trabalho, adquirem-se competências profissionais que traduzem o perfil do bom professor.

O que se evidencia aqui é que o trabalho docente no dia-a-dia (sic) é fundamentalmente um conjunto de interações personalizadas com os alunos para obter a participação deles em seu próprio sucesso de formação e atender a suas diferentes necessidades. Eis porque este trabalho exige, constantemente, um investimento profundo, tanto do ponto de vista afetivo cognitivo, nas relações humanas com os alunos. [...] um professor não pode somente "fazer seu trabalho" (grifos do autor), ele deve também empenhar e investir neste trabalho o que ele é mesmo como pessoa (TARDIF, 2002, p. 141).

Nesse sentido, não se pode conceber um professor com vidas distintas, isto é, uma no ambiente escolar e outra no ambiente social, como se fossem vias de mãos duplas que nunca se encontram, considerando-se que, na prática docente, o professor carrega para suas atividades profissionais os traços de toda a sua vivência fora do ambiente escolar.

\section{A formação do professor profissional}

As pesquisas sobre formação de professores e profissão docente apontam para uma revisão da compreensão da prática pedagógica do professor, que é tomado como mobilizador de saberes profissionais. Há aqui uma preocupação em separar formação e prática cotidiana, a partir da consideração da complexidade da prática pedagógica e dos saberes docentes.

A formação docente é ainda, na maioria das vezes, tratada no campo educacional como fato que deve ocorrer em tempos diferentes daqueles do efetivo trabalho docente. Porém entendemos, neste trabalho, que há de se buscar uma formação docente que ultrapasse os limites dos cursos de formação, como um continuum formativo.

Nessa perspectiva, Alvarado-Prada (1997) apresenta uma nova proposta para a formação docente, isto é, o processo formativo não deve acontecer, fundamentalmente, nos espaços e tempos que diferem respectivamente do tempo e espaços escolares, como se fossem práticas exteriores que ocorrem, portanto, fora da escola, fora da dinâmica escolar, geralmente em universidades e em centros de formação específicos.

A discussão sobre a prática professoral deve ser pensada como um momento de pedagogia, enfatizando que a formação docente não ocorre somente nos cursos de aperfeiçoamento oferecidos pelos órgãos competentes a cada novo modelo de ensino, ou de teoria, mas no contexto escolar, na dinamicidade da sala de aula e, no interior deste espaço, o professor também se forma.

Porém pensamos que esse modelo de formação ainda se encontra no campo do imaginário, porque a formação dos professores socialmente legitimada é feita em espaços especialmente destinados a esse fim, o que vai ao encontro ao que afirma Marques (2003, p. 55): "é no próprio exercício autônomo da profissão que se deve reconstruir o núcleo orgânico da atuação/formação".

A formação dos professores é questionada e colocada em xeque sempre que surgem um novo método ou uma nova política imposta pelo Estado, como por exemplo a Lei de Diretrizes e Bases da Educação Nacional (LDBEN),os Parâmetros Curriculares Nacionais (PCN's) ou mesmo quando é posta uma nova organização da escola em âmbito estadual. Assim, ao programar uma nova estrutura curricular nas escolas, muitas vezes os professores são responsabilizados pelo fracasso da organização anterior. É como se apenas a formação docente se justificasse para a solução de todos os problemas vivenciados no interior da escola (VEIGA, 1999).

Dessa forma, o suposto despreparo dos professores é visto como verdadeiro entrave aos avanços no projeto de escolarização dos alunos. A 
consequência mais imediata é que o professor é constantemente submetido a cursos de capacitação para aprimorar e reavaliar seus saberes.

No entanto, entendemos que o saber docente não é uma competência dada e não se define em uma atividade, isto é, apenas em cursos de capacitação. Ele é construído cotidianamente na disponibilidade de tornar-se professor, no espaço e no tempo do seu fazer pedagógico, no expor-se ao outro, e nele e com ele produz efeitos, desperta conhecimentos, habilidades e sensibilidades. Por isso, Tardif (2002, p. 149) afirma:

Se admitirmos que o saber dos professores não provém de uma fonte única, mas de várias fontes e de momentos da história de vida e de carreira profissional, essa própria diversidade levanta o problema da unificação e recomposição dos saberes pelo trabalho.

No sentido de apontar modelos de professores tradicionalmente aceitos, Contreras (2002) aponta para três formas de atuação de professores: o especialista técnico, o profissional reflexivo e o intelectual crítico. Vale salientar que esse autor critica essas três concepções naturalmente aceitas, por considerá-las insuficientes,quando não claramente equivocadas, para poder tratar da autonomia dos professores.

Dentre as três concepções apontadas acima, escolhemos para o comentário mais específico a do professor especialista técnico, por acreditar que é a mais se aproxima da prática dos professores do IFAM. Essa concepção, que tradicionalmente existiu na maioria das filosofias pedagógicas, parte da pressuposta neutralidade científica e é inspirada nos princípios da racionalidade técnica, eficiência e produtividade, os quais reordenam a decadência de memória e a torna objetiva e operacional, transformando-a em um simples trabalho fabril.

Nesse contexto, Contreras (2003, p. 90-1) descreve a racionalidade como:

A ideia básica do modelo de racionalidade técnica é que a prática profissional consiste na solução instrumental de problemas mediante a aplicação de um conhecimento teórico e técnico, previamente disponível, que proceda da pesquisa científica. É instrumental porque supõe a aplicação de técnicas e procedimentos que se justificam por sua capacidade para conseguir os efeitos ou resultados desejados.

Ora, se o trabalho do professor está pautado nessa premissa, ele, o professor, não passa de um operário, e o processo educativo é concebido nos moldes de correntes de uma fábrica, ou seja, o trabalhador ocupa seu posto de linha de montagem e executa determinada parcela do trabalho necessário para a produção de determinados objetos, onde o produto é, pois, uma decorrência da forma como é organizado o processo.

Assim, o professor, ao depender e/ou se portar como especialista técnico, contribui para aumentar o caos e a fragmentação que inviabilizam o processo pedagógico, agravando também o problema da marginalidade.

Não encontramos, em nossa pesquisa bibliográfica, projetos significativos de formação de professores para o Ensino Profissional. Sendo assim, as Escolas Técnicas, Centros Federais ou Instituto Federais de Educação, assim como todas as outras instituições que ministram essa modalidade de ensino, sempre sofreram e ainda sofrem com a falta de pessoal docente habilitado e qualificado para o magistério no Ensino Técnico.

Talvez seja por isso que o modelo de professor racional técnico seja o que mais se percebe em nossa prática docente no IFAM, e é isso que mostra a pesquisa de campo, que será explicitada no próximo item.

\section{Caracterizando o Professor do IFAM: a pesquisa de campo}

A amostra contemplou 15 professores e 30 alunos do Ensino Técnico de Nível Médio, porém, para esse trabalho, serão incluídos apenas os professores da modalidade Técnica, por entender que nesse período há uma maior expectativa por parte dos alunos que buscam principiar uma vida profissional.

Com relação às características pessoais, a maioria dos professores $(73 \%)$ concentra-se na faixa etária de 31 e 50 anos; apenas $7 \%$ têm entre 21 e 30 anos e $20 \%$ entre 51 e 60 anos. Da totalidade dos professores pesquisados, $27 \%$ são mulheres e $73 \%$ são homens.

Quanto aos cursos estudados, eles estão assim distribuídos: $47 \%$ cursaram Engenharia Elétrica; $32 \%$ cursaram Licenciatura; 7\%, Engenharia Civil; 7\%, o Programa Esquema II; 7\%, Bacharelado. Embora o programa Esquema II apareça com apenas uma indicação, a maioria dos 
professores pesquisa dos origina-se daquele programa, porém, após algum tempo, cursaram uma graduação regular.

Um fato que achamos importante ressaltar é que $26,6 \%$ dos professores participantes da pesquisa são egressos do próprio CEFET-AM e oriundos do Projeto de formação de professores Esquema I e Esquema II, porém cursaram uma graduação regular posteriormente. Isso representa que, embora não tenham passado por um curso de formação continuada de professores, eles próprios buscaram aperfeiçoamento, embora essa busca tenha se voltado para curso de Bacharelado e não de Licenciatura. Aí, talvez, esteja a origem das características tecnicistas dos docentes do Ensino Técnico, que se restringe basicamente a repassar o conhecimento adquirido na graduação.

Nesse modelo de professor, Contreras (2002, p. 95), entende que:

O reconhecimento que, como profissionais, os professores possuem, sob essa concepção, relaciona-se com o domínio técnico demonstrado na solução de problemas, ou seja, no conhecimento dos procedimentos adequados de ensino e em sua aplicação inteligente.

Quando perguntamos o porquê de trabalhar no Ensino técnico, $47 \%$ dos professores responderam que, por terem uma formação técnica, é natural que trabalhem com essa modalidade de ensino; $33 \%$ entendem que podem ajudar o aluno na aprendizagem e formação profissional; $13 \%$ por gostarem dessa modalidade; e $7 \%$ não responderam. Quanto à relevância dessa forma de ensino para a vida profissional dos professores, $60 \%$ dos professores afirmam que é uma forma de ajudar na prática profissional, colocando em prática os conhecimentos adquiridos no curso de graduação; 13\% gostam de trabalhar com o Ensino Profissional; $13 \%$ gostam de ver o resultado dos trabalhos técnicos empreendidos; 7\% têm no CEFET-AM sua única fonte de renda; e $7 \%$ não responderam.

Esses dados mostram o caminho natural dos professores do Ensino Profissional, ou seja, por serem egressos de uma educação técnica, logo, comumente, procuram levar para sua vida profissional esse mesmo modelo educativo, como podemos perceber na resposta do sujeito S8A, quando perguntamos porque escolheu trabalhar com o Ensino Técnico: "Por ter coerência com a minha formação acadêmica e com minha experiência profissional". Também o sujeito S10A esclarece: "Minha formação de nível médio foi profissionalizante na área da indústria: curso técnico em Eletrônica." Ou ainda, pelo sujeito S14A: "Pela formação técnica."

A partir dessas respostas, é natural que a maioria dos professores apresente à docência como uma forma de colocar em prática o conhecimento adquirido na graduação. Logo, se ele teve uma formação técnica, o professor tende a levar para sua sala de aula essa mesma prática. Isso vem corroborara colocação de Tardif sobre os saberes experienciais.

Os saberes experienciais fornecem aos professores certezas relativas a seu contexto de trabalho na escola, de modo a facilitar sua integração. Os saberes experienciais, possuem, portanto, três objetos: a) as relações $e$ interações que os professores estabelecem e desenvolvem com os demais atores no campo de sua prática; b)as diversas obrigações e normas às quais seu trabalho deve submeter-se; c) a instituição enquanto meio organizado $e$ composto de funções diversificadas. Esses objetos não são objetos de conhecimento, mas objetos de constituem a própria prática docente e que só se revelam através dela (TARDIF, 2002, p. 50).

Ainda com relação às perguntas em questão, uma resposta nos chamou atenção, por demonstrar como a docência pode ser vista como uma subrrenda, ou renda complementar, ou ainda, como falta de opção de trabalho: "É minha única fonte de renda já que não trabalho mais no distrito industrial e nem tenho empresa" (S4A). Nessa resposta podemos notar que o professor só está nessa posição docente por não haver uma outra fonte de renda. Tal afirmativa nos remete ao pensamento de Marques (2003), ao refletir sobre as condições para o bom exercício do magistério e/ou qualquer outra profissão:

Não se pode, na realidade, ganhar a vida senão no seu duplo sentido dessa expressão: garantir as condições da sobrevivência não pode separar-se do realizar os sentidos e valores pelos quais se vive, sob pena de o trabalho, a profissão, converter-se em forma de alienação pessoal e social (MARQUES, 2003, p. 57). 
Nesse sentido, o professor apresentaria um trabalho alienado, por não fazer a conexão entre o trabalho que exerce e com os sentidos próprios da vida pessoal, contrariando a posição do pensamento marxista sobre o trabalho.

Procuramos entender a concepção dos professores sobre ensino técnico em geral, donde obtivemos os seguintes resultados: $27 \%$ dos professores acham que o Ensino Técnico está bom e que ajuda o aluno a conseguir um emprego; $20 \%$ afirmam que este tipo de ensino não está bom; $13 \%$ não responderam; $7 \%$ entendem que o Ensino técnico não acompanha as novas tecnologias; $7 \%$ acreditam que deveria ser mais bem estruturado; $7 \%$ pensam que o Ensino Técnico limita os horizontes dos alunos; e 7\% acham que falta um maior entrosamento entre a escola e as empresas. Quando questionados sobre a qualidade dos currículos dos cursos técnicos em que trabalham, $47 \%$ dos professores afirmam que os currículos são bons; $39 \%$ pensam que não o são; $7 \%$ acham que está aceitável e 7\% acham que não está adequado.

Esses dois questionamentos demonstram que os professores, de modo geral, têm uma boa imagem do Ensino Técnico e os currículos com os quais trabalham. Fica clara também, a concepção desse ensino voltado explicitamente para o mercado de trabalho, sem se preocupar com os outros fatores que acompanham o processo educativo, incluindose aí o próprio exercício da cidadania.

Questionamos sobre as ações didáticopedagógicas realizadas antes de ministrarem as aulas: $27 \%$ dos professores responderam que preparam aulas; $27 \%$ preparam materiais didáticos, para serem utilizados em sala de aula, em especial, apostilas e materiais que utilizam multimídias; $13 \%$ preparam dinâmicas; $13 \%$ não responderam; 7\% apresentam os objetivos para os alunos e 7\% mostram a importância da disciplina aos alunos.

Perguntamos também sobre as ações didático-pedagógicas realizadas depois das aulas ministradas: $33 \%$ dos professores verificam a assimilação dos conteúdos; $27 \%$ aplicam exercícios de fixação; $7 \%$ preparam aula, corrigem provas; $7 \%$ fazem dinâmica de relaxamento; $7 \%$ reveem os conteúdos programáticos; $7 \%$ estabelecem relações entre os conteúdos e a realidade; $7 \%$ afirmam que não fazem nenhuma ação; e $7 \%$ não responderam.

Considerando que esses questionamentos se aproximam diretamente com a conceituação de pedagogia, as análises para essas respostas serão respaldadas no conceito de Pedagogia apresentado por Franco (2003, p. 11):

A pedagogia é voltada para a práxis educativa e "para atender à especificidade da práxis, há que ser uma ciência que se alimente da práxis e sirva de alimento a ela". "Terá por finalidade o esclarecimento reflexivo e transformador da práxis educativa". Evidentemente, nutrir-se-á também dos saberes criados pelas demais ciências que pesquisam a educação. Deve ainda ser uma ciência "críticoemancipatório", "de forma que a educação consiga concretizar sua vocação histórica de humanizar a humanidade, de diminuir as práticas excludentes e injustas" (grifos da autora).

O nosso intuito em mostrar esse conceito, o qual corroboramos, é demonstrar que as respostas apresentadas para os dois últimos questionamentos não apresentam nenhuma característica que se apoie nesse conceito. Sendo assim, o que nos fica é que as ações pedagógicas limitam-se ao preparo de conteúdos a serem ministrados. Dito de outra maneira, em nenhum momento percebe-se uma atitude didático-pedagógica coerente com o conceito de Pedagogia acima apresentado, revelando, mais uma vez, a prática tecnicista dos professores do local estudado.

Nesse sentido, os professores demonstram não ter um conceito claro do que seja a Pedagogia: parece haver uma redução de seu papel a um simples conjunto de técnicas. Porém entendemos que a identidade do professor deve, necessariamente, pautar-se pelo conhecimento e pela prática pedagógica, pois isso é que os diferencia dos demais profissionais.

Esse pensamento vai ao encontro do que afirma Marques (2003, p. 59): “A identidade da profissão de educador implica na formação dele a partir do caráter de unidade dos interessados em educação, que denominamos Pedagogia, como tal ciência do entendimento, da organização e da condução do trabalho docente".

$\mathrm{Na}$ pergunta seguinte buscamos entender o modelo de professor, se é que existe, que os professores costumam levar para a prática docente: $27 \%$ dos professores acreditam que o modelo a ser seguido deva ser daquele professor que ministra bem o conteúdo; 13\% não responderam; $13 \%$ seguem o modelo de Paulo Freire, mas não explicam que modelo é esse; $7 \%$ entendem que deve ser o modelo do professor facilitador da aprendizagem; 7\% seguem o modelo de Dewey, mas também não explicam; $7 \%$ acham que $\mathrm{o}$ modelo a ser seguido é o do professor dinâmico e amigo dos alunos; 7\%, o modelo do professor 
competente; 7\%, do professor tradicional e convencional; $7 \%$ não seguem nenhum modelo; e $7 \%$ seguem o modelo de professor que procura a participação dos alunos.

Deriva dessas respostas o caráter dado pelos professores à prática docente, cuja característica se restringe à explanação de conteúdos de uma forma satisfatória, considerando que a maioria entende dessa forma. Para enfatizar ainda mais essa característica, escolhemos para transcrição algumas respostas que confirmam essa nossa análise: S6A: "Se fazer entender o mais fácil possível". S1A: "De ministrar as aulas de acordo com a necessidade dos alunos, sem sair do conteúdo programático". S4A: "Não tenho modelo, porém acho que no mínimo o professor deve ministrar os conteúdos de maneira mais adequada ao aprendizado do aluno". Tentamos entrevistar os professores que optaram pelo modelo pedagógico de Paulo Freire, de Dewey ou de facilitador de aprendizagem, para tentar entender como eles concebem esse modelo, porém, mesmo depois da nova entrevista, não encontramos dados suficientes que resultem em uma análise.

Isso nos leva a dizer que os professores ouviram falar de tais modelos, mas não têm conhecimentos suficientes para descrevê-los e/ou relacionar aqueles modelos com a prática exercida por eles.

Buscamos saber dos professores o que entendem quando os alunos afirmam que "certos professores não têm didática, embora conheçam o conteúdo": $53 \%$ dos professores entendem que isso significa uma ação didática na qual os professores não conseguem fazer com que os alunos entendam o conteúdo; $20 \%$ acham que o professor não está conseguindo facilitar o conhecimento para o aluno; $13 \%$ negam ouvir tal comentário; $7 \%$ acham que isso ocorre quando o professor não se adapta à turma; e 7\% acham que isso representa um professor sem criatividade.

Entendemos que, mais uma vez, os professores apresentaram respostas que confirmam nossa análise deque eles restringem a prática docente ao bom exercício da transmissão dos conteúdos.

Um fato nos causa surpresa, aquele que aponta não ouvir tal comentário, pois foi a partir dessa colocação, por parte dos alunos, que chegamos a investigar tal item nesta pesquisa. Reafirmamos, então, que a prática docente ultrapassa os limites da mera explanação e, mesmo nessa explanação, o professor deve ser conhecedor dos conteúdos necessários para a boa docência, isto é, daqueles conhecimentos que ultrapassam o técnico e busca a formação integral do alunado.

Com relação aos conhecimentos necessários à docência, perguntamos quais seriam esses conhecimentos, se só aqueles relacionados aos componentes curriculares em que trabalham ou se haveria a necessidade de outros conhecimentos: $60 \%$ entendem que deveria haver um maior apoio didático e $40 \%$ acham que necessitam de mais materiais e equipamentos.

$\mathrm{Na}$ concepção desses professores, então, tal apoio seria dado sob a forma de técnicas e/ou didáticas para melhorar o desempenho docente e facilitar a aprendizagem dos alunos. Assim, os professores não conseguem perceber que somente ELES, no ambiente que só ELES conhecem, poderão definir essas técnicas e/ou didáticas para a melhoria do processo educativo. Resulta daí uma dependência de outros profissionais para pensarem o processo, próprio do racionalismo técnico.

Ressaltamos, entretanto, a necessidade de um professor integral, ou seja, um professor que conheça e assuma todo o processo educativo, como o conceito de artesão. Nossas ideias encontram embasamento no ideal de professor/educador apresentado por Marques (2003, p. 58): "Todo professor/educador deve ser esse profissional especializado em educação, educador por inteiro, capaz de conduzir o inteiro processo educativo: do pensar ao agir e fazer e avaliar".

Perguntamos aos professores se percebem a necessidade de terem conhecimentos pedagógicos para a docência do Ensino Técnico: 93\% dos professores afirmam que sim e $7 \%$ acham que apenas algumas vezes.

A seguir perguntamos se há a necessidade desses conhecimentos, qual a importância em realizar um trabalho pedagógico com os componentes curriculares com que trabalham e o porquê dessa importância: $86 \%$ dos professores acham que é importante porque facilita a prática docente e consequentemente a aprendizagem; 7\% não acham importante; e 7\% não responderam.

Averiguamos também se a falta desse conhecimento pedagógico dificulta ou facilita o exercício do trabalho docente e como isso acontece: $73 \%$ dos professores acreditam que dificulta, porque todo professor deveria ter certo conhecimento pedagógico, principalmente os professores do Ensino Técnico; $20 \%$ acham que facilita, porém parece haver uma divergência nas respostas apresentadas; e 7\% não responderam.

$\mathrm{Se}$ os conhecimentos pedagógicos são considerados necessários para o exercício da função docente, perguntamos aos professores que ações práticas poderiam ser adotadas para a satisfação dessa necessidade: para $53 \%$ dos professores é 
necessário um maior número de encontros didáticopedagógicos; $20 \%$ não responderam; $13 \%$ acham que deveriam buscar mais informações em fontes variadas; $7 \%$ pensam que os recursos de multimídia poderiam ser mais utilizados; e $7 \%$ entendem que a contextualização dos conteúdos ensinados através de textos poderia ajudar para aquela satisfação.

Essas respostas seguem a mesma linha de pensamento que insistimos em apresentar em nossas análises, ou seja, os professores sentem a necessidade de conhecimentos pedagógicos, pois para eles isso melhora a prática professoral. No entanto, esses conhecimentos se resumem a técnicas didáticas, como se houvesse receitas prontas e acabadas para a melhoria do ensino, representando a fragmentação entre o pensar o agir: os especialistas da educação estão para pensar e os professores para executar. Mais uma vez aparece o pensamento típico da racionalidade técnica, representando um pensamento pedagógico explicitado por Halliday (1990 apud Contreras, 2002, p. 95):

O conhecimento pedagógico relevante, a partir da mentalidade da racionalidade técnica, é sobretudo aquele que estabelece quais os meios mais eficientes para levar a cabo alguma finalidade predeterminada, ou seja,aquele que se pode apresentar como técnica ou método de ensino.

Assim, não cabe ao professor definir o que, como e quando o processo de ensino acontece, mas cabe aos profissionais especialistas trazerem os nortes que devem ser seguidos, à risca, pelos professores na prática da sala de aula.

Para a pergunta sobre o conceito de bom aluno, $100 \%$ apresentaram uma única resposta: o bom aluno é aquele que é participativo, interessado, questionador, cumpridor de suas obrigações. Já o mau aluno, para 93\% dos professores, é o oposto, é o aluno desinteressado, não participativo, faltoso, e para $7 \%$ é aquele aluno que só se preocupa com a nota.

O conteúdo dessas respostas indica a concepção de bom como um aluno capaz de cumprir tudo que a escola espera dele, além de, obviamente, procurar questionar a escola quando esta vai de encontro aos seus interesses pessoais, profissionais e/ou coletivo. Tal conceituação vai no sentido contrário ao conceito de tábula rasa, no qual o professor pode depositar todo um cabedal de conhecimento, sem levar em conta o conhecimento trazido pelo educando para sala de aula. Sendo assim, essa prática professoral da tábula rasa não tem a intenção, nem interesse, em formar alunos reflexivos, conscientes de seu papel social.
Nesse sentido o processo educativo "consiste em formar vontades que se conformem a determinado modelo de ação e cujo comportamento seja previsível. Então, o professor tem a obrigação de eliminar tudo o que leve a personalismos ou à autonomia pessoal" (FRANCO, 2003, p. 35).

\section{Considerações Finais}

A tradição educacional propedêutica tem como objetivo fundamental o desenvolvimento humano integral, com base em valores éticos, sociais e políticos, no sentido da preservação da dignidade do ser humano em sua totalidade. O Ensino Técnico, ao contrário, desenvolve-se consoante ao mercado de trabalho, ao domínio de métodos e técnicas, nos ditames da produtividade, eficácia e eficiência.

Nesse sentido, a pesquisa nos fez entender a relação intrínseca entre educação e mundo de trabalho, pois em geral este domina a educação, dada a necessidade de se formarem indivíduos e profissionais alinhados com as ideias produtivas em voga. Nesse pensamento pautam-se as diretrizes pedagógicas, pelo menos as que regem o Ensino Técnico.

Por sua vez, o educador do Ensino Técnico não pode se deixar levar apenas pelas as relações escola-mundo do trabalho, uma vez que a atividade docente envolve aspectos políticos, econômicos e sociais e, mais do que isso, tem uma dimensão ética, cuja legitimidade está ligada a esses fins.

Além disso, embora em nosso estudo com os professores do IFAM, não tenha apresentado, acreditamos que a prática docente sempre traz em si uma filosofia política, embora os professores não tenham consciência disso.

A partir do estudo, então, podemos afirmar que a prática docente dos professores Ensino Técnico tem sido a da racionalidade técnica. O professor, quando chega ao IFAM, já possui conhecimento sistematizado de sua área de atuação, com saberes tecnológicos contemporâneos. Para uma boa prática docente, então, cabe somar a esses conhecimentos os conhecimentos pedagógicos, o que vai tornar esse profissional detentor de mais um saber, o saber docente, porque na função docente o saber não se reduz à transmissão de conhecimentos concretos e sedimentados.

Os professores da instituição estudada ainda apresentam uma prática fundamentada nas "receitas" postas e/ou impostas por especialistas da educação para a melhoria do processo educativo. De certa forma, por não apresentarem um corpus de conhecimentos necessários à docência, tendo em vista que não passaram por um processo formativo 
que os tornasse verdadeiros professores, dado que eles geralmente são egressos dos bacharelados e, mesmo aqueles egressos de alguma licenciatura, após determinado tempo adequam-se às normas que regem os professores do Ensino Profissional, ou seja, o tecnicismo.

Nosso estudo demonstrou também que a maioria dos professores é muito influenciada pelas amarras burocráticas da organização escolar, ainda se encontra limitada a dar conta dos conteúdos das disciplinas como primeira finalidade de sua eficácia profissional e, por isso, ligada às práticas e aos métodos tradicionais de ensino.

Urge, então, fazer nascer um novo docente, cuja formação esteja pautada na ciência da educação, a Pedagogia, cujos pressupostos ultrapassam o conceito restrito de organização do trabalho pertencente a um sistema estruturado, tendo em vista o mercado de trabalho. Desse novo professor espera-se o crescente desenvolvimento ou (re) conhecimento de competências que lhes permitam enfrentar de forma original e criativa as mudanças educacionais pela apropriação das estruturas necessárias à práxis docente, e não apenas pela apropriação de conteúdos, que tem sido característica dos professores do IFAM.

\section{Referências}

ARROYO, Miguel G. Ofício de Mestre: imagens e auto-imagens. Petrópolis, RJ: Vozes, 2000.

_. Construindo a cidadania através da educação. Palestra proferida no Congresso Brasileiro de Educação e Cidadania: construindo a cidadania através da educação. Promovido por Ferrari Feiras e Eventos. Curitiba, PR, Agosto/2005.

ALVARADO-PRADA, Luis. E. Formação participativa de docentes em serviço. Taubaté, SP: Cabral Universitária, 1997, p. 107-140.
BRASIL, Lei de Diretrizes e Bases da Educação: (Lei 9.394/96) /apresentação Carlos Roberto Jamil Cury. 7. ed. Rio de Janeiro: DP \& A, 2004.

CONTRERAS, José. Autonomia de professores. Tradução de Sandra Trabucco Valenzuela. São Paulo: Cortez, 2002.

FRANCO, Maria Amélia S. Pedagogia como ciência de educação. Campinas, SP: Papirus, 2003. (Coleção Entre Nós Professores).

HYPÓliTO, A. Processo de trabalho na escola: algumas categorias para análise. In Teoria e educação, n.4, 1991.

MANFREDI, Silvia M. Educação Profissional no Brasil. São Paulo: Cortez, 2002.

MARCELO GARCIA, Carlos. Formação de professores: para uma mudança educativa. Porto: Porto Editora, 1999.

MARQUES, Mario O. Formação de profissional de educação. - 4. ed. - Ijuí: Editora Unijui,2003

RAMALHO, Betânia L.; NUNEZ, Isauro Beltrán; GAUTHIER, Clermart. Formar o professor, profissionalizar o ensino - perspectivas e desafios. 2. ed. - Porto Alegre: Sulic, 2004.

SAVIANI, Demerval. Escola e democracia. - 8. ed. - São Paulo: Cortez, 1985 (Coleção polêmicas do nosso tempo, v. 5).

TARDIF, Maurice. Saberes docentes $e$ profissionais. Petrópolis, RJ: Vozes, 2002.

VEIGA, Ilma Passos A. Formação de Professores e os Programas Especiais de Complementação Pedagógica. In: Desmistificando a profissionalização do magistério. Campinas, SP: Papirus, 1999. (Coleção Magistério: Formação e Trabalho Pedagógico).

\section{Sobre o autor}

Ailton Gonçalves Reis é professor efetivo do Instituto Federal do Amazonas-IFAM; Mestre em Educação pela Universidade de Uberaba-UNIUBE; Doutorando em Educação pela Pontifícia Universidade de Minas Gerias PUC Minas.

Recebido em setembro de 2014.

Aprovado em maio de 2015. 